Bernier, A., Beauchamp, M.H., Carlson, S.M., \& Lalonde, G. (2015). A secure base from which to regulate: Attachment security in toddlerhood as a predictor of executive functioning at school entry. Developmental Psychology, 51, 1177-1189. 


\begin{abstract}
In light of emerging evidence suggesting that the affective quality of parent-child relationships may relate to individual differences in young children's executive functioning (EF) skills, the aim of this study was to investigate the prospective associations between attachment security in toddlerhood and children's EF skills in kindergarten. Mother-child dyads $(\mathrm{N}=105)$ participated in two toddlerhood visits in their homes, when children were 15 months and 2 years of age. Mother-child attachment security was assessed with the Attachment Q-Sort during both these visits. When children were in kindergarten (ages 5-6), they were administered a battery of EF tasks, and their teachers completed the Behavior Rating Inventory of Executive Function to assess children's EF problems. The results indicated that kindergarteners who were more securely attached to their mothers in toddlerhood showed better performance on all EF tasks, and were considered by their teachers to present fewer EF problems in everyday school situations. These results held above family SES and child age, sex, and general cognitive functioning. The fact that early attachment security uniquely predicted both teacher reports and children's objective EF task performance suggests that parent-child attachment may be a promising factor to consider in the continuing search for the social antecedents of young children's EF.
\end{abstract}

Keywords: attachment security, executive functioning, kindergarten, school entry. 


\section{A secure base from which to regulate: Attachment security in toddlerhood as a predictor of executive functioning at school entry}

The transition to kindergarten and elementary school is considered one the most significant developmental milestones of early childhood (Pianta, Cox, \& Snow, 2007). Even for children who have already attended preschool or daycare, numerous changes characterize entry into kindergarten: adjusting to a new teacher, a new peer group, a larger child-to-adult ratio, an unfamiliar school environment, and less time for free play along with a heightened orientation toward learning (Ladd \& Price, 1987). Decades of empirical research have shown that successful negotiation of this transition has lasting and significant consequences for academic, social and behavioral outcomes in childhood (see Ladd, 2004) and adolescence (e.g., Schofield, Bierman, Heinrichs, \& Nix, 2008).

One set of skills that is increasingly recognized as critical for fostering children's social and academic adjustment at school entry is executive functioning (EF), a set of higher-order cognitive processes that are predominantly subsumed by frontal brain areas, particularly the prefrontal cortex (Stuss, 2011). Executive functions include impulse control, set-shifting, and working memory, and take a managerial role in the monitoring of goal-directed, self-regulated thinking and behavior (Carlson, Zelazo, \& Faja, 2013). These functions are presumed to be foundational for social and academic competence in young children (Blair, 2002), in that they underlie many abilities required for successful management of classroom and school demands including the ability to strategically focus and disengage attention as needed, maintain concentration, resist interference in class or during social exchanges, learn from one's academic or interpersonal errors, control the urge to react to social provocation inappropriately, and so on (Bierman, Nix, Greenberg, Blair, \& Domitrovich, 2008). Overall, kindergarteners with better EF 
are considered to possess richer cognitive and behavioral regulation skills, which allow them to engage effectively in active learning and develop collaborative and harmonious relationships with teachers and peers (Blair \& Raver, 2014; Williford, Vick Whittaker, Vitiello, \& Downer, 2013). In line with these claims, empirical research shows that better EF performance relates to higher social (Hughes \& Ensor, 2008) and academic competence in young children (Bull, Espy, \& Wiebe, 2008; Willoughby, Blair, Wirth, \& Greenberg, 2012), including across the transition to school (Blair, Ursache, Greenberg, \& Vernon-Feagans, 2015; Hughes \& Ensor, 2011; NICHD Early Child Care Research Network, 2003).

EF thus appears to be a critical set of tools for negotiating the transition to kindergarten and elementary school, likely to set young children on a developmental pathway that may impact their school trajectory for years to come (Moffitt et al., 2011). Accordingly, it appears vital to understand the environmental factors that may explain individual differences in children's EF at school entry. The last few years have seen the emergence of a marked research interest in one such potential influence: the quality of parent-child relationships.

\section{Parent-child relationships and children's EF}

It has long been proposed that early relational experiences should have a substantial impact on brain development (e.g., Nelson \& Bloom, 1997). This would be in part attributable to the brain's remarkable plasticity during the first years of life, characterized by over-production of synapses followed by a prolonged period of gradual pruning (Huttenlocher, 2002). During this period, experience is considered to determine to a large degree which synaptic connections persist and are strengthened by frequent use, and which are progressively eliminated due to inactivity (see Greenough \& Black, 1992). This process is presumed to be especially marked in the prefrontal cortex, the brain area that shows the most protracted post-natal development 
(Giedd et al., 1999; Sowell, Trauner, Gamst, \& Jernigan, 2002). Many have argued that this largely post-natal development leaves a substantial window of opportunity for environmental input to impact the development of frontal brain systems and related EF (e.g., Kolb et al., 2012; Noble, Norman, \& Farah, 2005).

As one of the earliest, most intense, and most enduring experiences of childhood, the parent-child relationship is perhaps the most salient aspect of young children's early environment. For this reason, parenting has often been proposed as likely to impact children's developing frontal brain structures (Belsky \& de Haan, 2011; Gunnar, Fisher, \& the Early Experience Stress and Prevention Science Network, 2006; Kraybill \& Bell, 2013) and, thus, EF (Carlson, 2003; Hughes \& Ensor, 2005; Landry, Miller-Loncar, Smith, \& Swank, 2002). In line with these claims, several studies have found that specific task-oriented behaviors used by parents during joint problem solving, notably autonomy support, attention support, and scaffolding (Bernier, Carlson, \& Whipple, 2010; Conway \& Stifter, 2012; Hammond, Müller, Carpendale, Bibok, \& Liebermann-Finestone, 2012; Hughes \& Ensor, 2009) are related to better child performance on independent EF tasks. Notwithstanding the robustness of these findings, it is likely that other indicators of the quality of parent-child relationships may prove useful as well in explaining individual differences in child EF. Indeed, it is well-documented that parent-child relationships are multidimensional, and that different dimensions make unique contributions to child functioning (see Grusec \& Davidov, 2010, for a review). In fact, there is evidence of these other influences in the EF literature: aspects of mother-child interactions that do not pertain to problem solving, but rather describe the global affective quality of the relationship (e.g., positive, non-intrusive parenting; mutually responsive interactions; positive affect; maternal warmth; positive emotional verbal tone; maternal sensitivity), have been found to relate to child EF (Blair 
et al., 2011; Cuevas et al., 2014; Kraybill \& Bell, 2013; Rochette \& Bernier, 2014) or closely related constructs, such as effortful control (Cipriano \& Stifter 2010; Kochanska, Murray, \& Harlan, 2000; Taylor, Eisenberg, Spinrad, \& Widaman, 2013). Thus, while there is no doubt that specific task-oriented aspects of parental behavior are relevant to children's EF, it appears that broader affective features of parent-child relationships are important too.

Perhaps one of the most widely recognized indicators of the affective quality of parentchild relationships is attachment security, or the quality of the emotional bond between a child and his or her primary caregivers (see Cassidy \& Shaver, 2008). This recognition is well justified by longitudinal studies spanning over more than 20 years of development (see Grossmann, Grossmann, \& Waters, 2005), as well as meta-analytic reviews (e.g., Fearon, BakermansKranenburg, Van IJzendoorn, Lapsley, \& Roisman, 2010), showing that the security of early attachment relationships between children and their caregivers is a reliable predictor of children's developmental pathways. Consequently, parent-child attachment relationships are largely considered to be a critical aspect of young children's early experience.

A putative influence of early attachment security on child EF development can be expected due to the well-attuned external regulation provided by competent caregivers (Kopp, 1982), especially when children face emotionally or cognitively challenging situations (Calkins, 2011). It is proposed that the quality of the affective bond characterizing secure attachment relationships provides a safe and orderly relational context in which children can gradually learn to master the self-regulated thought and action that define EF (Kochanska \& Aksan, 1995; Lewis \& Carpendale, 2009), for instance through harmonious joint play activities that facilitate children's practice and integration of executive skills (Landry \& Smith, 2010; Perez \& Gauvain, 2010). Through repeated experiences of successful regulation guided by a competent caregiver, 
securely attached children are thought to internalize the skills acquired and to gradually integrate them in their own repertoire of independent self-regulation skills (Calkins, 2004). In other words, the hypothesis is that emotional and cognitive regulatory processes are first practiced in the context of attachment relationships (Sroufe, 1996), and are then generalized and used outside of the dyadic relationship, such as during tasks requiring independent self-regulation (Calkins, 2004; Cole, Martin, \& Dennis, 2004), a defining feature of EF tasks.

Overall, there are solid theoretical grounds to expect associations between the security of early parent-child attachment relationships and child EF. Yet, the relevant empirical evidence is remarkably scant. Two studies have used representational measures of attachment along with concurrent measures of children's EF to study these variables' respective contributions to subsequent externalizing behavior problems. These two studies report, in their preliminary analyses, that disorganized attachment representations are associated with lower inhibition capacity at age 5 (Bohlin, Eninger, Brocki, \& Thorell, 2012) and with general executive deficits at age 8 (Thorell, Rydell, \& Bohlin, 2012). Given, though, that studying the direct links between attachment and EF was not the aim of these studies, the authors did not examine whether the links were robust to covariates, and did not test longitudinal predictions, raising the possibility that the reported associations may have been spurious or inflated. As noted above, these studies also used narrative methods to infer children's attachment representations.

To our knowledge, only two studies have examined actual attachment behavior in relation to child EF performance, or proxies thereof. Von der Lippe, Eilertsen, Hartmann, and Killèn (2010) used the Strange Situation Procedure (Ainsworth, Blehar, Waters, \& Wall, 1978) at one year of age to assess mother-child attachment, and a task known as the Running Horses Game Test (RHGT; Hartmann \& Haavind, 1981), at age 6, to assess child EF and related problem- 
solving behaviors. This task is considered to tap into rule mastery, decision-making, adequate interest, inadequate reaction, passivity, competing, and adequate emotion, as well as aspects more usually associated with executive functions: inhibitory control, working memory, planning, and cognitive flexibility. Using a factor score to represent the core of children's performance on the task as measured by these scales, the authors found a positive association between early attachment security and children's overall performance on the RHGT. Given the approach used, though, it is difficult to ascertain the extent to which the observed associations apply to child EF specifically, rather than general problem-solving skills and attitudes.

Finally, based on analyses run on a portion (59\%) of the current study's sample, we reported that a composite of mother-child attachment security at 15 months and 2 years of age, assessed with the Attachment Behavior Q-Sort (AQS; Waters, 1995), was positively related to child performance on a battery of EF tasks (Carlson, 2005) at age 3 (Bernier, Carlson, Deschênes, \& Matte- Gagné, 2012). In light of the critical importance of EF at school entry described above, we were now interested in longer-term longitudinal predictions. Accordingly, the current study set out to investigate the links between early mother-child attachment security and children's executive performance at age 5-6, in kindergarten. Owing to the documented link between child general cognitive ability and EF, we controlled for child general cognition (in this case, cognitive school readiness), in order to draw conservative and specific predictions. It was expected that toddlers more securely attached to their mothers at ages 15 months and 2 years would grow up to show superior EF in kindergarten, over and above their general cognitive ability. 


\section{Method}

\section{Participants}

The current sample consisted of 58 of the original 62 mother-child dyads who took part in the first study three years earlier (Bernier et al., 2012), in addition to 47 other dyads that were recruited at a later time but took part in all assessments. The sample for this study was therefore composed of 105 families (47 boys and 58 girls). Families lived in a large Canadian metropolitan area and were recruited from birth lists randomly generated and provided to the research team by the Ministry of Health and Social Services. Criteria for participation were full-term pregnancy and the absence of any known physical or mental disability or severe delay. Family income varied from less than $\$ 20,000 \mathrm{CDN}$ to over $\$ 100,000 \mathrm{CDN}$, with an average in the $\$ 60,000$ to $\$ 79,000$ bracket. Most mothers (85\%) and fathers (77\%) were Caucasian. Mothers were between 20 and 45 years old $(M=31.3)$, and fathers between 22 and 44 years old $(M=33.4)$. Both mothers and fathers had 15.4 years of education on average, varying from 10 to 18 for mothers, and from 11 to 21 for fathers.

The 105 families with complete data were part of a larger sample of 128 families who had attachment data at 15 months. Thus, the retention rate was $82.0 \%$, with 23 families leaving the study at the 2-year, 3-year, 4-year (not used here), or kindergarten time point. Attrition analyses revealed that families who left the study were not different from others on demographic or attachment variables. Only one difference approached significance: mothers who dropped out had marginally fewer years of education $(M=14.7, S D=2.7)$ than mothers who stayed in the study $(M=15.5, S D=2.4), t(126)=1.97, p=.07$.

\section{Procedure}


The families took part in two toddlerhood visits, when children were 15 months $(\mathrm{T} 1 ; M=$ $15.5, S D=0.76)$ and 2 years of age $(\mathrm{T} 2 ; M=25.9$ months, $S D=1.39)$, as well as in a kindergarten visit when children were in the Spring of their kindergarten year (February through April - T3; $M=72.3$ months, $S D=2.50$ ). Although duration of schooling (i.e., number of weeks since the beginning of the academic year) at the moment of the EF assessment was not expected to impact EF scores (and indeed, was unrelated to EF indices, all $r$ 's $<.11, p$ 's $\geq .25$ ), it may obscure relations with attachment, and was thus co-varied in all final models.

All visits were conducted in the families' homes, and lasted 70 to 90 minutes. The first two home visits (T1 and T2) were modeled after the work of Pederson and Moran (1995), and purposely designed to create a situation where maternal attention was being solicited by both the research tasks and the toddler's demands. This was intended to reproduce the need for multitasking that is inherent to caring for a toddler in daily life. Both visits included child-centered tasks, a brief interview with the mother, a videotaped mother-infant interactive sequence, and questionnaires that mothers had to complete while the toddler was not looked after by the research assistant. Observations performed throughout these two visits were used to rate child attachment security. Graduate observers, trained per Pederson and Moran's recommendations described below, conducted these ratings. The last visit (T3), also conducted in the families' homes, mainly consisted in the administration of the EF tasks described below. Upon parents' agreement (97/105 parents accepted), the research team sent the BRIEF (see below) by mail to the child's kindergarten teacher, asking him or her to complete and return the questionnaire in a pre-paid envelope. Most (85/97) contacted teachers returned the questionnaire. The 20 families for whom no teacher assessment was available did not differ from the other 85 families on sociodemographics, attachment, or EF task performance (all $p$ 's $>.12$ ). The missing data were 
handled with multiple imputation (as recommended by Schlomer, Bauman, \& Card, 2010) so as to have equivalent sample sizes $(\mathrm{N}=105)$ for all EF outcomes (see below for details).

In order to maximize the reliability of observations of child attachment behavior, we followed Pederson and Moran's (1995) recommendations for training our AQS raters. Research assistants first attended a two-day training workshop pertaining to techniques of home visiting and observation of mother-child interactions. They reviewed several videotapes of mother-child interactions in order to practice using the AQS. The assistants then performed their first few home visits with a more experienced colleague, and they completed the AQS together. When the junior assistants were deemed ready to rate child attachment, the next few visits were followed by a debriefing session with an experienced graduate student, in order to review the salient elements of the visit before scoring the AQS. Double-coding for inter-rater reliability purposes took place only after the research assistants had successfully completed this process.

\section{Measures}

Mother-child attachment security. Child attachment was assessed at both 15 months and 2 years using the Attachment Behavior Q-Sort (AQS; Waters, 1995), which was completed immediately after the home visits, based on observations performed throughout. The AQS has been used with children between 1 and 6 years of age (Van IJzendoorn et al., 2004). It is comprised of 90 items describing potential child behaviors. Items are sorted by an observer into nine piles, reflecting the degree to which the items resemble the child under observation (ranging from very unlike to very similar to his or her behavior). The observer's sort is then correlated with a criterion sort provided by the authors of the instrument, representing the prototypically securely attached child. Attachment scores can thus vary from $-1=$ most insecure to $1=$ prototypically secure. Prototypical security in the AQS represents a fluid balance between 
exploration of the environment and appropriate reliance on the caregiver for soothing and support when needed, as indicated by high scores on items such as "If held in mother's arms, child stops crying and quickly recovers after being frightened or upset" or "If mother reassures him, child will approach or play with things that initially made him cautious or afraid", along with low scores on items such as "Child stays closer to mother or returns to her more often than the simple task of keeping track of her requires" or "Child rarely asks mother for help."

At T1, inter-rater reliability was conducted for $26.7 \%(n=28)$ of the dyads and was found to be ICC $=.71$. At T2, it was conducted for $28.6 \%(n=30)$ of the dyads and was ICC $=$ .72. Meta-analytic data (Van IJzendoorn et al., 2004) suggest that the observer-AQS shows excellent construct validity, with attachment scores converging with maternal sensitivity, attachment security assessed with the Strange Situation, and child adaptation. The AQS also shows moderate temporal stability (meta-analytic $r=.28$; Van IJzendoorn et al., 2004). In line with this, the correlation between attachment security at 15 months and 2 years in the current study was $r=.22, p<.05$. In order to reduce measurement and situational error and create a reliable index of attachment security, we averaged the two AQS scores into a global score of child attachment security, used in all further analyses. In five cases where the AQS score was missing at 2 years, the 15-month score was used. No families had attachment data at 2 years but not at 15 months.

Child executive functioning. Children's EF at age 5 was assessed with both a battery of EF behavioral tasks and a teacher report.

\section{Battery of EF tasks.}

Backward Word Span (Carlson, Moses, \& Breton, 2002). This measure was adapted from the classic Digit Span task (Davis \& Pratt, 1996) to be better suited to children whose numerical 
skills are still developing, which might inadvertently impact their task performance. The experimenter asked children to repeat a list of single-syllable, familiar, yet non-semantically related words in the reverse order (e.g., if E says, "cup, book," then the child is to say, "book, cup"). List size increased with each successful trial, and the task ended when the child erred three consecutive times at a given level. This task has been found to correlate with other EF measures in the preschool-kindergarten period (Bierman et al., 2008; Carlson \& Harrod, 2013). Dimensional Change Card Sort (DCCS; Zelazo, 2006). The experimenter showed children a card depicting a red truck, and a card depicting a blue star, and explained that they would play a sorting game with two boxes, which were labeled with a blue truck and a red star (thus in contrast with the test cards). In the first round, children were instructed to classify the cards handed to them, one by one, by shape ( 6 trials). In the second round, they were instructed to switch rules and sort the cards by color (6 trials). These first two rounds are known to be easy for 5- or 6-year-old children, and indeed our sample was at ceiling, with over $97 \%$ of children obtaining perfect scores. These rounds serve to set the stage for the third round, which is the actual test phase for this age. In the third round, children had to sort by either shape or color, based on whether or not there was a border around the card - they had to sort by color when handed a card with a border, and by shape if handed a card with no border (6 trials). As mentioned above, only scores for the third round were used. Total scores could thus vary between 0 and 6. The DCCS has excellent test-retest reliability and validity (Beck, Schaefer, Pang, \& Carlson, 2011; Weintraub et al., 2013; Zelazo et al., 2013). Internal consistency is also excellent ( $\alpha=.93$; Bierman et al., 2008), and was satisfactory in this sample $(\alpha=.72)$.

NEPSY Tower. Planning skills were assessed using the NEPSY tower task (Korkman, Kirk, \& Kemp, 1998), an adapted version of the original Tower of London measure (Shallice, 
1982). In this version, children are presented with a model in which three colored beads (red, blue, yellow) are positioned on three pegs of different heights, which can hold either one, two, or three beads. After arranging the beads according to a predetermined starting position, participants are shown a target arrangement and asked to reproduce this model by moving the beads in a prescribed number of moves, ensuring that only one bead is displaced at a time. Executive planning scores are determined on the basis of twenty trials of increasing difficulty, according to the number of trials completed in the prescribed number of moves. Total scores could thus vary from 0 to 20 . In samples of 5 and 6-year-old children, the tower task demonstrates satisfactory test-retest reliability ( $r=.75$; Korkman et al., 1998).

Flanker. This computerized measure of selective attention was adapted from the Attention Network Task (Rueda et al., 2004) for the NIH Toolbox Cognition Battery by Zelazo and colleagues (2013). A monitor depicted fish in a line, and either they were all facing in the same direction (congruent trials) or the middle fish was facing in the opposite direction (incongruent trials). Following a brief practice period, children were instructed to use one of two arrow keys on the keyboard to indicate which direction the middle fish was pointing (left or right; 25 trials). If they succeeded on at least 5 out of the 9 incongruent trials in this block (all children in this sample did), they proceeded to a final block in which the fish were replaced with smaller arrows (thus making it more challenging) for 25 more trials. Accuracy (percent correct of total trials) was used in data analyses. The Toolbox Flanker task shows excellent developmental sensitivity, test-retest reliability, and convergent validity in this age group (Carlson \& Harrod, 2013; Weintraub et al., 2013; Zelazo et al., 2013). Internal consistency was satisfactory in this sample $(\alpha=.73)$. 


\section{Teacher report: The Behavior Rating Inventory of Executive Function - Preschool}

Version (BRIEF; Gioia, Espy, \& Isquith, 2003). The BRIEF was used to obtain teacher ratings of participants' emotional, behavioral, and functional manifestations of executive dysfunction. The BRIEF is a standardized questionnaire including 63 items (1-3 Likert scale) targeting five specific subdomains of EF. The first two, Inhibit and Emotional Control, are combined to form the Inhibitory Self-Control Index (hereafter Self-Control). The Shift and Emotional Control subdomains compose the Flexibility Index (Flexibility). The other two subdomains, Working Memory and Plan/Organize, form the Emergent Metacognition Index (Metacognition). The three index scores (Self-Control, Flexibility, Metacognition) were used as outcome measures in the present study. A higher score suggests an increased level of executive problems. The preschool version of the BRIEF has good psychometric properties, including adequate internal consistency ( $\alpha=.80-.97)$ and satisfactory test-retest reliability ( $r=.65-.94$; Gioia et al., 2003). In the current sample, internal consistency was respectively .96, .93, and .93 for Self-Control (26 items), Flexibility (20 items), and Metacognition (27 items).

Child cognitive ability. In order to tap into what is uniquely executive beyond general cognitive ability, we used the letter knowledge subscale of the Lollipop test (Chew \& Morris, 1984). The Lollipop is a well-validated test that assesses the cognitive and language skills underlying school readiness (Lemelin et al., 2007). It is composed of four subscales: knowledge of colors and shapes, of spatial notions (beside, under, etc.), of numbers, and of letters. It has been shown to predict school achievement up to 4th grade (Chew \& Morris, 1989; Eno \& Woehlke, 1995; Lemelin et al., 2007). The letter knowledge subscale ( $\alpha=.81$ in the current sample; $\alpha=.93$ in Lemelin et al., 2007) was of particular interest because it is a strong unique predictor of $1^{\text {st }}$-grade school achievement, above and beyond child age, sex, and the other 
Lollipop subscales (which each explain less than a third of the unique variance accounted for by letter knowledge; Lemelin \& Boivin, 2007).

Prior levels of child executive functioning: 3-year assessment. At 3 years, a battery of EF tasks was used, consisting of the following tasks (see Bernier et al., 2012, for a more detailed description). (i) Bear/Dragon (Reed, Pien, \& Rothbart, 1984): Children were asked to follow the "nice" bear's requests (e.g., touch your nose) but to refrain from following the "naughty" dragon's requests (10 trials). (ii) Day/Night (Gerstad, Hong, \& Diamond, 1994): Children were asked to say "day" when they were shown a card depicting the moon, and "night" when shown the sun (16 trials). (iii) DCCS (Zelazo, 2006). As described above. Only the first two rounds were administered at age 3 .

We previously reported (Bernier et al., 2012) that these tasks constituted one factor (Conflict-EF), which was related to early attachment security. Accordingly, in a last set of analyses, we will co-vary this 3-year Conflict-EF score to examine whether attachment security predicts changes in EF between age 3 and kindergarten.

\section{Results}

\section{Preliminary analyses}

To maximize the sample size and thus diminish the probability of Type-II error, cases with missing values (on the BRIEF) were included in the analyses by estimating missing data. The multiple imputation procedure available in SPSS 20.0 was used to impute BRIEF data. Five imputations were used, with missing data estimated from all other EF data available. All subsequent analyses were performed on each of the imputed data sets, and results for each were then averaged (Schafer, 1997). 
Table 1 presents the descriptive statistics for the key study variables. All distributions were within bounds of moderate normality (skewness $<3.0$; kurtosis $<7.0$; Curran, West, \& Finch, 1996; Kline, 1998), although teachers generally perceived few executive problems in the children, and performance on the Flanker task was generally very good. Data were next screened for extreme scores. No multivariate outliers were found, but one univariate outlier was found on the AQS, two on the Flanker, and three across the three BRIEF dimensions. In all cases, these scores were substituted with the highest (or lowest) observed value that fell within $+/-3.29$ standardized scores (Tabachnick \& Fidell, 2013).

The degree of relations among the different EF indicators (task-based and teacherreported) was examined next (Table 2). Overall, EF task scores were mildly to moderately associated amongst themselves and with the BRIEF scores, while the BRIEF scores were moderately to highly inter-related, which is common for indirect observer report measures (e.g., Schmitt, Pratt, \& McClelland, 2014). The inter-correlations among the EF task scores were similar to those observed by Willoughby et al. (2012) on an independent larger sample of sameage children. The highest correlation was that between self-control and flexibility $(r=.82, p<$ $.001)$, which was expected given that the Emotional Control subdomain (10 items) contributes to both indices. Owing to this pattern of findings, revealing a good deal of both shared and unique variance across EF indicators, it was deemed best to run analyses on each EF indicator as well as on composite scores. To derive these composites, the seven EF scores (Backward word span, DCCS, NEPSY tower, Flanker, and three BRIEF indices) were submitted to a principal component analysis, which yielded a two-factor solution (Eigen values > 1.0) representing $58.7 \%$ of the total variance. These two factors were submitted to an oblique principal axis rotation. The first factor essentially represented the BRIEF: self-control $(\lambda=.93)$, flexibility $(\lambda=$ 
$.92)$, and metacognition $(\lambda=.72)$, whereas the EF task scores loaded on the second factor:

Flanker $(\lambda=.82)$, Backward word span $(\lambda=.65)$, DCCS $(\lambda=.64)$, and NEPSY tower $(\lambda=.45)$.

The correlation between the two factors was -.40. In light of these results, two composite scores were considered in analyses: the BRIEF Executive Composite score, which consist of the average of all 63 items, as well as the standardized average of the four EF tasks (Backward word span, DCCS, NEPSY tower, Flanker).

We then examined the zero-order correlations between child EF and socio-demographics (child age, sex, birth order, and family SES) as well as child performance on the Lollipop's letter knowledge test. Overall, the results were in line with the literature: studies often find relations between child EF and child age and cognitive ability as well as family SES, but rarely with sex or birth order. As displayed in Table 3, child age was negatively related to all BRIEF indices of EF problems, and positively related to Backward word span and to overall EF task performance. Family SES was negatively related to the BRIEF index of metacognition problems, and positively related to Backward word span, Flanker, overall EF task performance, and marginally associated with the DCCS. Child sex was related to the metacognition index of the BRIEF only, and birth order was unrelated to EF indices. Finally, letter knowledge was associated with Backward word span, overall EF task performance, and with all BRIEF scores. In light of these results, and in order to run conservative and uniform analyses, child age, sex, and letter knowledge, as well as family SES, were co-varied in all final regression models. As mentioned above, duration of school experience was also controlled for.

\section{Main analyses}

Table 3 also presents the zero-order correlations between the composite of attachment security and child EF scores. All correlations were significant and in the expected directions: 
greater attachment security was related to better subsequent EF task performance and to fewer EF problems as perceived by teachers.

In order to test the robustness of these links, the data were submitted to hierarchical regression analyses. Each EF score was submitted to a different equation. In a first block of each equation, we entered the potential confounds mentioned above: child sex, age, and letter knowledge, as well as family SES and the number of weeks of school up to the assessment day. The composite score of attachment security was entered in a second block, to test its unique contribution to variation in child EF above the covariates.

Table 4 presents the results of the analyses pertaining to teachers' assessment of child executive difficulties in school. The models predicted between $13.7 \%$ and $22.3 \%$ of variance across the four indices. After controlling for the covariates, early attachment security predicted unique additional variance in flexibility $(\beta=-.21, p=.036)$, metacognition $(\beta=-.21, p=.035)$, and the global executive composite $(\beta=-.24, p=.013)$, and made a marginal contribution to the prediction of self-control $(\beta=-.16, p=.087)$. In all four cases, relations were in the expected direction: children who were observed to be more securely attached to their mothers in toddlerhood were considered by their kindergarten teachers to present fewer deficits in flexibility, metacognition, and (marginally) self-control at school, as well as fewer executive deficits overall. Attachment security predicted between $2.5 \%$ and $5.4 \%$ of unique variance in teachers' assessment of child executive difficulties in school.

Table 5 presents the results of the analyses pertaining to child performance of the behavioral EF tasks. The models predicted between $9.6 \%$ and $32 \%$ of variance in child EF task performance. After accounting for the set of covariates, child attachment security made incremental contributions to the prediction of child performance on all four EF tasks [Backward 
word $\operatorname{span}(\beta=.18, p=.042), \operatorname{DCCS}(\beta=.24, p=.018), \operatorname{NEPSY}$ tower $(\beta=.25, p=.013)$, and Flanker $(\beta=.20, p=.041)]$, as well as to the prediction of child overall performance $(\beta=.29, p$ $=.002$ ). Children who were rated as more securely attached to their mothers in toddlerhood performed better on all aspects of the EF task battery at age 5-6, above and beyond the variance explained by family SES, weeks of schooling, and child sex, age, and general cognitive ability. Overall, attachment security predicted between $3.1 \%$ and $8.0 \%$ of unique variance in child EF task performance.

\section{Supplemental analyses: Predicting changes in EF}

Given our prior results linking early attachment security to age-3 Conflict-EF (but not Impulse Control; Bernier et al., 2012) we ran a last set of analyses focusing on changes in EF, that is, controlling for age-3 Conflict-EF when predicting EF in kindergarten. The results were quite similar to those presented above, with the exception of child performance on Backward word span. In that case, results indicated that although early attachment was uniquely related to child performance as observed in kindergarten $(\beta=.18, p=.042$, as presented above), it was not related to the portion of kindergarteners' performance on Backward word span that was not explained by their earlier Conflict-EF performance $(\beta=.12, p=.207)$. In all other cases, the unique contributions of attachment security to the portion of kindergarteners' EF that was not explained by their earlier Conflict-EF performance were similar to those presented above in magnitude, and remained within the same statistical significance threshold brackets.

\section{Discussion}

School entry has sometimes been described as one of the most striking transitions that a person experiences in his or her lifetime (Haith \& Sameroff, 1996). Given the numerous changes that characterize this transition, children's EF skills are likely to be frequently solicited, as 
children face new challenges of both an academic and social nature. Often, the novelty of the situations encountered in the new school and the new peer group will preclude reliance on automatic, well-learned habits of solving problems and interacting with others, and instead require the use of executive control skills. Children, however, are not equal in the face of such challenges; research shows that individual differences in children's EF across the transition to school are substantial, and carry important implications for their social and academic adjustment (Blair et al., 2015; Hughes \& Ensor, 2011; NICHD Early Child Care Research Network, 2003). The current study suggests that part of these individual differences can be traced back years earlier in development. We investigated the capacity of mother-child attachment security, assessed as early as almost five years prior to school entry, to predict individual variation in two aspects of child EF in kindergarten: teachers' perceptions of children's executive deficits as manifested in their everyday functioning at school, and children's performance on standard EF behavioral tasks, administered independently. The results suggested that individual differences in those aspects of children's EF were reliably associated with the quality of their earlier attachment relationships with their mothers: kindergarteners who were more securely attached to their mothers in toddlerhood showed better performance on EF tasks, and were considered by their teachers to present fewer EF problems in everyday school situations.

Importantly, these attachment-EF links are specific: they cannot be accounted for by family SES, which underlies both parenting and child EF, nor do they reflect the well-known, more general effect of high-quality parenting and secure attachment on children's cognitive functioning, assessed here with a measure of cognitive school readiness. Instead, the results suggest that even when holding family SES, child general cognition, and other potential confounds constant, kindergarteners who were securely attached to their mothers in toddlerhood 
come to kindergarten equipped with a superior set of executive skills essential to their successful negotiation of the school transition. Interestingly, this was observed both on standard laboratory tasks and in independent teacher reports, which each have their unique strengths and drawbacks. While behavioral EF tasks are objective and thus free of respondent bias, one may question their ecological validity; in contrast, the BRIEF is more vulnerable to respondent subjectivity, however it focuses on everyday manifestations of EF in the natural school environment, as observed by the child's teacher over several months (6 to 8 months in this case). The BRIEF may thus capture subtle EF difficulties that may be activated in challenging "real-life" situations (e.g., change in routine, noise or confusion in the classroom), and that might go undetected in a controlled research situation (Riccio, Hewitt, \& Blake, 2011). Standardized EF tasks, however, provide a more uniform assessment across children, and target the fundamental cognitive functions that subsume children's day-to-day functioning. All in all, the fact that early attachment security uniquely predicted both teacher reports and children's objective EF task performance provides confidence in the reliability of the results.

In fact, the results were quite uniform across the different EF indicators, whether teacherreported or task-based, although only two of these indicators (BRIEF-derived self-control and flexibility) were highly inter-correlated. The measures that we used assessed a variety of executive functions, including working memory, inhibition, cognitive flexibility, and planning, both teacher-reported and objectively assessed. Yet, the results were somewhat similar across these EF indicators. This appears to suggest that if the links to attachment are causal in nature, the effects may be broad rather than specific, in other words, that secure attachment relationships may promote young children's global executive competence (and/or promote skills or structures that subsume all EF skills), rather than have specific effects on particular executive functions. 
This conclusion is in line with research suggesting a unidimensional structure of EF at age 5 (e.g., Willoughby et al., 2012), and is further supported by the observation that results in the current study tended to be slightly stronger in magnitude with the composite scores than with individual task scores or BRIEF indices. A set of secondary results suggested that most findings remained quite similar when accounting for already documented links between early attachment and children's Conflict-EF at age 3, except for performance on Backward word span, a quasipure measure of working memory. It may be worthy of note that likewise, our age-3 Conflict-EF tasks entailed a good deal of working memory requirements; thus, putative effects of early attachment on kindergarteners' EF may be mediated, in some cases, by an intermediate impact of attachment on similar cognitive functions earlier in development.

There are a number of other pathways through which a putative influence of early attachment on child executive competence could transit. As outlined above, it is believed that secure attachment relationships provide children with repeated exposure to successful experiences of dyadic regulation in cognitively or emotionally challenging contexts. Metaanalytic data show that caregivers of securely attached children are more adept at teaching their children adequate problem-solving strategies to handle challenging situations, and do so within a warmer, more harmonious emotional climate (De Wolff \& Van IJzendoorn, 1997). As a result, securely attached children are believed to gradually internalize these strategies and eventually use them independently (Calkins, 2004). Hence, secure attachment relationships may provide children not only with "a secure base from which to explore" (Ainsworth et al., 1978), but also, and importantly, with specific emotional and cognitive skills for successful exploration, thereby supporting their developing self-regulatory capacities. 
In addition to such direct teaching of EF-like skills, secure attachment may also have an indirect effect, transiting through children's neurobiological structures. As mentioned earlier, a putative impact of early caregiving relationships on frontal brain structures is often invoked to explain why higher-quality parenting relates to better child EF. Although this hypothesis has yet to be tested, emerging evidence is beginning to provide support for its components. Indeed, it has recently been observed that higher-quality mother-infant interactions predict infants' increased brain activity (EEG power) at frontal locations (Bernier, Calkins, \& Bell, in press), which itself predicts better subsequent EF in the preschool years (Kraybill \& Bell, 2013). Thus, it may be that securely attached children show more optimal functioning of frontal brain systems, which would pave the way to the orderly development of executive skills. This is speculative, however, and future longitudinal studies are needed to test such a mediation hypothesis.

Should such a process be corroborated, it might itself be subsumed by more basic psychophysiological factors. It has been proposed that responsive, nurturing caregiving may have a soothing effect on children's biology, facilitating homeostasis and supporting the modulation of physiological arousal (Porges \& Furman, 2011). In support of this, recent research suggests that securely attached children show more optimal functioning of both sympathetic and parasympathetic branches of the autonomous nervous system (Bernard \& Dozier, 2010; Luijk et al., 2010; Oosterman, De Schipper, Fisher, Dozier, \& Schuengel, 2010). It has further been observed (Mizoguchi, Ishige, Takeda, Aburada, \& Tabira, 2004) that stress hormone levels can affect synaptic activity in the very brain regions that subsume EF and in fact, Blair et al. (2011) observed that basal cortisol production partly mediates some of the links they observed between parenting and child EF. Hence, stress physiology may be another pathway through which 
attachment security could influence child EF, potentially through an intermediate impact on frontal brain regions (see Gunnar et al., 2006).

An alternative hypothesis for the results is that mothers' own EF, which was not assessed here, might underlie both mother-child attachment security and child EF. Although to our knowledge, maternal EF has never been investigated as a potential antecedent of mother-child attachment, studies have found that maternal EF relates to both child EF (Cuevas, DeaterDeckard, Kim-Spoon, Wang, et al., 2014; Hughes \& Ensor, 2009) and maternal caregiving (Cuevas, Deater-Deckard, Kim-Spoon, Watson, et al., 2014), which itself is an important predictor of mother-child attachment (Bernier, Matte-Gagné, Bélanger, \& Whipple, 2014). Hence, it may be that mothers who have better executive capacities transmit these capacities to their children, for instance through direct scaffolding or child observational learning (Hughes \& Ensor, 2009), while also being better equipped to provide the type of calm, consistent, and regulating caregiving that will give rise to secure attachment. While it has also been postulated that the transmission of maternal EF onto child EF may be genetically driven (e.g., Cuevas, Deater-Deckard, Kim-Spoon, Watson, et al., 2014), shared genetic characteristics appear somewhat unlikely to have played an important role in the results reported here. Indeed, several genetically-informed studies show that the variance in mother-child attachment (Bokhorst et al., 2003; O’Connor \& Croft, 2001; Roisman \& Fraley, 2008) and the covariance between parenting and child attachment (Fearon et al., 2006) is almost entirely due to environmental influences, with small genetic contributions. Thus, a genetic explanation for the current results appears unlikely; however, an environmentally-driven effect of maternal EF on both child attachment and child EF is an exciting explanatory hypothesis for the results reported here. 
This study presents limitations that qualify the conclusions that can be drawn, while suggesting directions for future research. First, the portions of variance explained by early attachment, while reliable across EF indicators, were modest in magnitude. Accordingly, there can be no doubt that there is much more to early childhood EF than mother-child attachment. Most obviously, father-child attachment (or fathering more generally) deserves far more attention than it has received in the EF literature. Furthermore, many other biological and environmental factors not assessed here, including maternal EF and child stress physiology and brain development, are likely to play a significant role in the early development of EF. As mentioned earlier, mean levels of teacher-reported executive problems were low. Although not unexpected with a low-risk sample like the current one, and suggesting that early attachment can predict mild variation in child EF, this reduced variability does imply that the current results may not generalize to higher-risk populations in which more severe executive deficits are likely to be observed (e.g., children with ADHD). The homogeneous and low-risk nature of the sample may also explain why some of the expected links between family SES and child EF (Table 3) were not found. Importantly, the current design was longitudinal yet correlational; therefore, the associations observed may not be indicative of causal relations between attachment and EF. Experimental manipulation of attachment security is, however, becoming possible: a metaanalysis of intervention studies revealed that brief, evidence-based intervention can alter the quality of parent-child relationships and promote secure attachments (Bakermans-Kranenburg, Van IJzendoorn, \& Juffer, 2003). The use of empirically validated interventions to foster secure attachment, along with careful assessment of child EF pre- and post-intervention, would provide a strong experimental test of the presumed influence of attachment security on child EF. 
This study suggested that children who had been more securely attached to their mothers in toddlerhood performed better on EF tasks once they reached kindergarten, and were considered by their teachers to present fewer executive deficits. While the mechanisms underlying these links have yet to be identified and causality investigated, the current findings add to a recent yet rapidly growing literature suggesting that a psychobiological framework is insufficient to explain variability in young children's EF, and that social influences need to be taken seriously as well. 


\section{References}

Ainsworth, M. D. S., Blehar, M. C., Waters, E., \& Wall, S. (1978). Patterns of Attachment: A Psychological Study of the Strange Situation. Hillsdale, NJ: Erlbaum.

Bakermans-Kranenburg, M. J., Van IJzendoorn, M. H., \& Juffer, F. (2003). Less is more: Metaanalyses of sensitivity and attachment interventions in early childhood. Psychological Bulletin, 129, 195-215. doi: 10.1037/0033-2909.129.2.195

Beck, D. M., Schaefer, C., Pang, K., \& Carlson, S. M. (2011). Executive function in preschool children: Test-retest reliability. Journal of Cognition and Development, 12, 169-193. doi: $10.1080 / 15248372.2011 .563485$

Belsky, J. \& de Haan, M. (2011). Annual research review: Parenting and children's brain development: the end of the beginning. Journal of Child Psychology and Psychiatry, 52, 409-428. doi: 10.1111/j.1469-7610.2010.02281.x

Bernard, K., \& Dozier, M. (2010). Examining infants' cortisol responses to laboratory tasks among children varying in attachment disorganization: Stress reactivity or return to baseline? Developmental Psychology, 46, 1771-1778. doi: 10.1037/a0020660

Bernier, A., Calkins, S.D., \& Bell, M.A. (in press). Longitudinal associations between the quality of maternal parenting behavior and brain development across infancy. Child Development.

Bernier, A., Carlson, S.M., Deschênes, M., \& Matte- Gagné, C. (2012). Social factors in the development of early executive functioning: A closer look at the caregiving environment. Developmental Science, 15, 12-24. doi: 10.1111/j.1467-7687.2011.01093.x

Bernier, A., Carlson, S. M., \& Whipple, N. (2010). From external regulation to self-regulation: Early parenting precursors of young children's executive functioning. Child Development, 81, 326-339. doi: 10.1111/j.1467-8624.2009.01397.x 
Bernier, A., Matte-Gagné, C., Bélanger, M.-E., \& Whipple, N. (2014). Taking stock of two decades of attachment transmission gap: Broadening the assessment of maternal behavior. Child Development, 85, 1852-1865. doi: 10.1111/cdev.12236

Bierman, K. L., Nix, R. L., Greenberg, M. T., Blair, C., \& Domitrovich, C. E. (2008). Executive functions and school readiness intervention: Impact, moderation, and mediation in the Head Start REDI program. Development and Psychopathology, 20, 821-843. doi:

$10.1017 / \mathrm{S} 0954579408000394$

Blair, C. (2002). School readiness: Integrating cognition and emotion in a neurobiological conceptualization of children's functioning at school entry. American Psychologist, 57, 111127. doi: 10.1037/0003-066X.57.2.111

Blair, C., Granger, D., Willoughby, M., Mills-Koonce, R., Cox, M., Greenberg, M. T., ... \& the FLP Investigators (2011). Salivary cortisol mediates effects of poverty and parenting on executive functions in early childhood. Child Development, 82, 1970-1984. doi: 10.1111/j.1467-8624.2011.01643.x

Blair, C., \& Raver, C. C. (2014). School readiness and self-regulation: A developmental psychobiological approach. Annual Review of Psychology, 66, 12.1-12.21. doi: 10.1146/annurev-psych-010814-015221

Blair, C., Ursache, A., Greenberg, M., \& Vernon-Feagans, L. (2015). Multiple aspects of selfregulation uniquely predict mathematics but not letter-word knowledge in the early elementary grades. Developmental Psychology, 51, 459-472. doi: 10.1037/a0038813 
Bohlin, G., Eninger, L., Brocki, K. C., \& Thorell, L. B. (2012). Disorganized attachment and inhibitory capacity: Predicting general externalizing problem behaviors and specific psychopathological symptoms. Journal of Abnormal Child Psychology, 40, 449-458. doi: $10.1007 / \mathrm{s} 10802-011-9574-7$

Bokhorst, C. L., Bakermans-Kranenburg, M. J., Fearon, R. M., Van IJzendoorn, M. H., Fonagy, P., \& Schuengel, C. (2003). The importance of shared environment in mother-infant attachment security: A behavioral genetic study. Child Development, 74, 1769-1782. doi: 10.1046/j.1467-8624.2003.00637.x

Bull, R., Espy, K. A., \& Wiebe, S. A. (2008). Short-term memory, working memory, and executive functioning in preschoolers: Longitudinal predictors of mathematical achievement at age 7 years. Developmental Neuropsychology, 33, 205-228. doi:

$10.1080 / 87565640801982312$

Calkins, S. D. (2004). Early attachment process and the development of emotional selfregulation. In R. F. Baumeister \& K. D. Vohs (Eds.), Handook of self-regulation: Research, theory, and applications (pp. 324-339). New York: Guilford Press.

Calkins, S. D. (2011). Caregiving as coregulation: Psychobiological processes and child functioning. In A. Booth, S.M. McHale, \& N.S. Landale (Eds.), Biosocial Foundations of Family Processes (pp. 49-59). New York: Springer.

Carlson, S. M. (2003). Executive function in context: Development, measurement, theory, and experience. Monographs of the Society for Research in Child Development, 68, 138-151. doi: 10.1111/j.1540-5834.2003.06803012.x

Carlson, S. M. (2005). Developmentally sensitive measures of executive function in preschool children. Developmental Neuropsychology, 28, 595-616.doi: 10.1207/s15326942dn2802_3 
Carlson, S. M., \& Harrod, J. (2013, April). Validation of the executive function scale for early childhood. In J. Griffin (Chair), Developing the Next Generation of Preschool Outcome Measures: The Interagency School Readiness Measurement Consortium. Poster symposium presented at the biennial meeting of the Society for Research in Child Development. Seattle, WA.

Carlson, S. M., Moses, L. J., \& Breton, C. (2002). How specific is the relation between executive function and theory of mind? Contributions of inhibitory control and working memory. Infant and Child Development, 11, 73-92. doi: 10.1002/icd.298

Carlson, S. M., Zelazo, P. D., \& Faja, S. (2013). Executive function. In P. D. Zelazo (Ed.), The Oxford Handbook of Developmental Psychology (vol. 1, pp. 706-743). New York: Oxford University Press.

Cassidy, J., \& Shaver, P. R. (2008). Handbook of attachment: Theory, research, and clinical applications $\left(2^{\text {nd }}\right.$ ed.). New York: Guilford Press.

Chew, A. L., \& Morris, J. D. (1984). Validation of the Lollipop test: A diagnostic screening test of school readiness. Educational and Psychological Measurement, 44, 987 - 991. doi: $10.1177 / 0013164484444022$

Chew, A. L., \& Morris, J. D. (1989). Predicting later academic achievement from kindergarten scores on the Metropolitan Readiness Tests and the Lollipop Test. Educational and Psychological Measurement, 49, 461 - 465. doi: 10.1177/0013164489492019

Cipriano, E.A., \& Stifter, C.A. (2010). Predicting preschool effortful control from toddler temperament and parenting behavior. Journal of Applied Developmental Psychology, 31, 221-230. doi: 10.1016/j.appdev.2010.02.004 
Cole P. M., Martin S. E., \& Dennis T. A. (2004). Emotion regulation as a scientific construct: Methodological challenges and directions for child development research. Child Development, 75, 317-333. doi: 10.1111/j.1467-8624.2004.00673.x

Conway, A., \& Stifter C. A. (2012). Longitudinal antecedents of executive function in preschoolers. Child Development, 83, 1022-1036. doi: 10.1111/j.1467-8624.2012.01756.x

Cuevas, K., Deater-Deckard, K., Kim-Spoon, J., Wang, Z., Morasch, K.C., \& Bell, M.A. (2014). A longitudinal intergenerational analysis of executive functions during early childhood. British Journal of Developmental Psychology, 32, 50-64. doi:10.111/bjdp.12021

Cuevas, K., Deater-Deckard, K., Kim-Spoon, J., Watson, A. J., Morasch, K. C., \& Bell, M. A. (2014). What's mom got to do with it? Contributions of maternal executive function and caregiving to the development of executive function across early childhood. Developmental Science, 17, 224-238. doi: 10.1111/desc.12073

Curran, P. J., West, S. G., \& Finch, J. F. (1996). The robustness of test statistics to nonnormality and specification error in confirmatory factor analysis. Psychological Methods, 1, 16-29. doi:10.1037/1082-989X.1.1.16

Davis, H. L., \& Pratt, C. (1996). The development of children's theory of mind: The working memory explanation. Australian Journal of Psychology, 47, 25-31. doi: $10.1080 / 00049539508258765$

De Wolff, M. S., \& Van IJzendoorn, M. H. (1997). Sensitivity and attachment: A meta-analysis on parental antecedents of infant attachment. Child Development, 68, 571-591. doi: 10.1111/j.1467-8624.1997.tb04218.x 
Eno, L., \& Woehlke, P. (1995). Use of the Lollipop Test as a predictor of California Achievement Test scores in kindergarten and transitional first-grade status. Psychological Reports, 76, 145-146. doi: 10.2466/pr0.1995.76.1.145

Fearon, R. P., Bakermans-Kranenburg, M. J., van ljzendoorn, M. H., Lapsley, A. M., \& Roisman, G. I. (2010). The significance of insecure attachment and disorganization in the development of children's externalizing behavior: a meta-analytic study. Child Development, 81, 435-356. doi: 10.1111/j.1467-8624.2009.01405.x

Fearon, R. P., Van IJzendoorn, M. H., Fonagy, P., Bakermans-Kranenburg, M. J., Schuengel, C., \& Bokhorst, C. L. (2006). In search of shared and nonshared environmental factors in security of attachment: A behavior-genetic study of the association between sensitivity and attachment security. Developmental Psychology, 42, 1026-1040. doi: 10.1037/00121649.42.6.1026

Gerstad, C. L., Hong, Y. J., \& Diamond, A. (1994). The relationship between cognition and action: Performance of children 3 1/2 -7 years old on a Stroop-like day-night test. Cognition, 53, 129-153.

Giedd, J. N., Blumenthal, J., Jeffries, N. O., Castellanos, F. X., Liu, H., Zijdenbos, A., ... \& Rapoport, J. L. (1999). Brain development during childhood and adolescence: A longitudinal MRI study. Nature Neuroscience, 2, 861-863. doi:10.1038/13158

Gioia, G. A., Espy, K. A., \& Isquith, P. K. (2003). Behavior Rating Inventory of Executive Function - Preschool Version (BRIEF-P). Odessa, FL: Psychological Assessment Resources. 
Greenough, W. T., \& Black, J. E. (1992). Induction of brain structure by experience: Substrates for cognitive development. In M. R. Gunnar \& C. A. Nelson (Eds.), Developmental Behavioural Neuroscience (pp. 155-200). Hillsdale, NJ: Erlbaum.

Grossmann, K. E., Grossmann, K., \& Waters, E. (2005). Attachment from infancy to adulthood: The major longitudinal studies. New York, NY: Guilford Press

Grusec, J. E., \& Davidov, M. (2010). Integrating different perspectives on socialization theory and research: A domain-specific approach. Child Development, 81, 687-709. doi: 10.1111/j.1467-8624.2010.01426.x

Gunnar, M. R., Fisher, P. A., \& the Early Experience Stress and Prevention Network. (2006). Bringing basic research on early experience and stress neurobiology to bear on preventive interventions for neglected and maltreated children. Development and Psychopathology, 18, 651-677. doi: 10.1017/S0954579406060330

Haith, M. M., \& Sameroff, A. J. (1996). The five to seven year shift: Retrospect and prospect. In A. J. Sameroff \& M. M. Haith (Eds.), The five to seven year shift: The age of reason and responsibility (pp. 435-449). Chicago, Il: University of Chicago Press.

Hammond, S. I., Müller, U., Carpendale, J. I. M., Bibok, M. B., \& Liebermann-Finestone, D. P. (2012). The effects of parental scaffolding on preschoolers' executive function.

Developmental Psychology, 48, 271-281. doi: 10.1037/a0025519

Hartmann, E., \& Haavind, H. (1981). Mothers as teachers and their children as learners. In W. Robinson (Ed.), Communication in development. European Monographs in Social Psychology (pp. 129-158). London: Academic Press.

Hughes, C., \& Ensor, R. (2005). Executive function and theory of mind in 2 year-olds: A family affair? Developmental Neuropsychology, 28, 645-668. doi: 10.1207/s15326942dn2802_5 
Hughes, C., \& Ensor, R. (2008). Does executive function matter for preschoolers' problem behaviors? Journal of Abnormal Child Psychology, 36, 1-14. doi: 10.1007/s10802-0079107-6

Hughes, C., \& Ensor, R. (2009). How do families help or hinder the emergence of early executive function? New Directions for Child and Adolescent Development, 123, 35-60. doi: $10.1002 / \mathrm{cd} .234$

Hughes, C., \& Ensor, R. (2011). Individual differences in growth in executive function across the transition to school predict externalizing and internalizing behaviors and children's selfperceived academic success at age 6. Journal of Experimental Child Psychology, 108, 663676. doi: 10.1016/j.jecp.2010.06.005

Huttenlocher, P. R. (2002). Neural plasticity: The effects of environment on the development of the cerebral cortex. Cambridge, MA: Harvard University Press.

Kline, R. B. (1998). Principles and practice of structural equation modeling. New York: Guilford.

Kochanska, G., \& Aksan, N. (1995). Mother-child mutually positive affect, quality of child compliance to requests and prohibitions, and maternal control as correlates of early internalization. Child Development, 66, 236-254. doi: 10.2307/1131203

Kochanska, G., Murray, K. T., \& Harlan, E. T. (2000). Effortful control in early childhood: Continuity and change, antecedents, and implications for social development. Developmental Psychology, 36, 220-232. doi: 10.1037/0012-1649.36.2.220

Kolb, B., Mychasiuk, R., Muhammad, A., Li, Y., Frost, D. O., \& Gibb, R. (2012). Experience and the developing prefrontal cortex. Proceedings of the National Academy of Sciences of the United States of America, 109, 17186-17193. doi: 10.1073/pnas.1121251109 
Kopp, C. B. (1982). Antecedents of self-regulation: A developmental perspective.

Developmental Psychology, 18, 199-214. doi: 10.1037/0012-1649.18.2.199

Korkman, M., Kirk, U., \& Kemp, S. (1998). NEPSY: A developmental neuropsychological assessment. San Antonio, TX: The Psychological Corporation.

Kraybill, J. H., \& Bell, M. A. (2013). Infancy predictors of preschool and post-kindergarten executive function. Developmental Psychobiology, 55, 530-538. doi: 10.1002/dev.21057

Ladd, G. W. (2004). Probing the adaptive significance of children's behavior and relationships in the school context: A child by environment perspective. Advances in Child Behavior and Development, 31, 43-104.

Ladd, G. W. \& Price, J. M. (1987). Predicting children's social and school adjustment following the transition from preschool to kindergarten. Child Development, 58, 1168-1189. doi: 10.1111/j.1467-8624.1987.tb01450.x

Landry, S. H., Miller-Loncar, C. L., Smith, K. E., \& Swank, P. R. (2002). The role of early parenting in children's development of executive processes. Developmental Neuropsychology, 21, 15-41. doi: 10.1207/S15326942DN2101_2

Landry, S. H., \& Smith, K. E. (2010). Early social and cognitive precursors and parental support for self-regulation and executive function: Relations from early childhood into adolescence. In B. W. Sokol, U. Müller, J. I. M. Carpendale, A.R. Young, \& G. Iarocci (Eds.), Self and social regulation: Social interaction and the development of social understanding and executive functions (pp. 386-417). New York, NY: Oxford University Press.

Lemelin, J.-P., \& Boivin, M. (2007). Success starts in Grade 1: The importance of school readiness. Retrieved from the Quebec Statistical Institute website: www.jesuisjeserai.stat.gouv.qc.ca 
Lemelin, J.-P., Boivin, M., Forget-Dubois, N., Dionne, G., Séguin, J. R., Brendgen, M., . . Pérusse, D. (2007). The genetic-environmental etiology of cognitive school readiness and later academic achievement in early childhood. Child Development, 78, 1855-1869. doi: 10.1111/j.1467-8624.2007.01103.x

Lewis, C., \& Carpendale, J. I. M. (2009). Introduction: Links between social interaction and executive function. In C. Lewis \& J. I. M. Carpendale (Eds.), Social interaction and the development of executive function: New Directions in Child and Adolescent Development (pp. 1-15). New York: Jossey Bass.

Luijk, M. P., Saridjan, N., Tharner, A., Van IJzendoorn, M. H., Bakermans-Kranenburg, M. J., Jaddoe, V. W., . . . Tiemeier, H. (2010). Attachment, depression, and cortisol: Deviant patterns in insecure-resistant and disorganized infants. Developmental Psychobiology, 52, 441-452. doi: 10.1002/dev.20446

Mizoguchi, K., Ishige, A., Takeda, S., Aburada, M., \& Tabira, T. (2004). Endogenous glucocorticoids are essential for maintaining prefrontal cortical cognitive function. Journal of Neuroscience, 23, 5492-5499. doi: 10.1523/JNEUROSCI.0086-04.2004

Moffitt, T. E., Arseneault, L., Belsky, D., Dickson, N., Hancox, R. J., Harrington, H., ... Caspi, A. (2011). A gradient of childhood self-control predicts health, wealth, and public safety. Proceedings of the National Academy of Sciences of the United States of America, 108, 2693-2698. doi: 10.1073/pnas.1010076108

Nelson, C. A., \& Bloom, F. E. (1997). Child development and neuroscience. Child Development, 68, 970-987. doi: 10.1111/j.1467-8624.1997.tb01974.x 
NICHD Early Child Care Research Network (2003). Do children's attention processes mediate the link between family predictors and school readiness? Developmental Psychology, 39, 581-593. doi: 10.1037/0012-1649.39.3.581

Noble, K. G., Norman, M. F., \& Farah, M. J. (2005). Neurocognitive correlates of socioeconomic status in kindergarten children. Developmental Science, 8, 74-87. doi: 10.1111/j.1467-7687.2005.00394.x

O’Connor, T. G., \& Croft, C. M. (2001). A twin study of attachment in preschool children. Child Development, 72, 1501-1511. doi :10.1111/1467-8624.00362

Oosterman, M., De Schipper, J. C., Fisher, P., Dozier, M., \& Schuengel, C. (2010). Autonomic reactivity in relation to attachment and early adversity among foster children. Development and Psychopathology, 22, 109-118. doi: 10.1017/S0954579409990290

Pederson, D. R., \& Moran, G. (1995). A categorical description of infant-mother relationships in the home and its relation to Q-sort measures of infant-mother interaction. Monographs of the Society for Research in Child Development, 60, 111-145. doi: 10.2307/1166174

Perez, S. M., \& Gauvain, M. (2010). Emotional contributions to the development of executive functions in the family context. In B. W. Sokol, U. Müller, J. I. M. Carpendale, A.R. Young, \& G. Iarocci (Eds.), Self and social regulation: Social interaction and the development of social understanding and executive functions (pp. 358-380). New York: Oxford University Press.

Pianta, R. C., Cox, M. J., \& Snow, K. L. (2007). School readiness and the transition to kindergarten in the era of accountability. Baltimore, MD: Paul H Brookes Publishing. 
Porges, S. W., \& Furman, S. A. (2011). The early development of the autonomic nervous system provides a neural platform for social behaviour: A polyvagal perspective. Infant and Child Development, 20, 106-118. doi: 10.1002/icd.688

Reed, M. A., Pien, D., \& Rothbart, M. K. (1984). Inhibitory self-control in preschool children. Merrill-Palmer Quarterly, 30, 131-147.

Riccio, C. A., Hewitt, L. L., \& Blake, J. J. (2011). Relation of measures of executive function to aggressive behavior in children. Applied Neuropsychology, 18, 110. doi: $10.1080 / 09084282.2010 .525143$

Rochette, É., \& Bernier, A. (2014). Parenting, family socio-economic status and child executive functioning: A longitudinal study. Merrill-Palmer Quarterly, 60, 431-460. doi: 10.1353/mpq.2014.0024

Roisman, G. I., \& Fraley, R. C. (2008). A behavior-genetic study of parenting quality, infant attachment security, and their covariation in a nationally representative sample. Developmental Psychology, 44, 831-839. doi: 10.1037/0012-1649.44.3.831

Rueda, M. R., Fan, J., McCandliss, B. D., Halparin, J. D., Gruber, D. B., Lercari, L. P., \& Posner, M. I. (2004). Development of attentional networks in childhood. Neuropsychologia, 42, 1029-1040. doi: 10.1016/j.neuropsychologia.2003.12.012

Schafer, J. L. (1997). Analysis of Incomplete Multivariate Data. London: Chapman \& Hall.

Schmitt, S. A., Pratt, M. E., \& McClelland, M. M. (2014). Examining the validity of behavioral self-regulation tools in predicting preschoolers' academic achievement. Early Education and Development, 25, 641-660. doi: 10.1080/10409289.2014.850397 
Schlomer, G. L., Bauman, S., \& Card, N. A. (2010). Best practices for missing data management in counseling psychology. Journal of Counseling Psychology, 57, 1-10. doi: $10.1037 / \mathrm{a} 0018082$

Schofield, H. T., Bierman, K. L., Heinrichs, B., \& Nix, R. L. (2008). Predicting early sexual activity with behavior problems exhibited at school entry and in early adolescence. Journal of Abnormal Child Psychology, 36, 1175-1188. doi: 10.1007/s10802-008-9252-6

Shallice, T. (1982). Specific impairments of planning. Philosophical Transactions: Biological Sciences, 298, 199-209. doi: 10.1098/rstb.1982.0082

Sowell, E. R., Trauner, D. A., Gamst, A., \& Jernigan, T. L. (2002). Development of cortical and subcortical brain structures in childhood and adolescence: A structural MRI study. Developmental Medicine and Child Neurology, 1, 4-16. doi: 10.1111/j.14698749.2002.tb00253.x

Sroufe, L. A. (1996). Emotional development: The organization of emotional life in the early years. New York: Cambridge University Press.

Stuss, D. T. (2011). Functions of the frontal lobes: Relation to executive functions. Journal of the International Neuropsychological Society, 17, 759-765. doi: 10.1017/S1355617711000695

Tabachnick, B. G., \& Fidell, L. S. (2013). Using Multivariate Statistics (6th ed). Boston: Allyn and Bacon.

Taylor, Z. E., Eisenberg, N., Spinrad, T. L., \& Widaman, K. F. (2013). Longitudinal relations of intrusive parenting and effortful control to ego-resiliency during early childhood. Child Development, 84, 1145-1151. doi: 10.1111/cdev.12054 
Thorell, L. B., Rydell, A. M., \& Bohlin, G. (2012). Parent-child attachment and executive functioning in relation to ADHD symptoms in middle childhood. Attachment and Human Development, 14, 517-532. doi: 10.1080/14616734.2012.706396

Van IJzendoorn, M. H., Vereijken, C. M., Bakermans-Kranenburg, M. J., \& Riksen-Walraven, J. M. (2004). Assessing attachment security with the Attachment Q Sort: Meta-analytic evidence for the validity of the observer AQS. Child Development, 75, 1188-1213. doi: 10.1111/j.1467-8624.2004.00733.x

Von der Lippe, A., Eilertsen, D. E., Hartmann, E., \& Killèn, K. (2010). The role of maternal attachment in children's attachment and cognitive executive functioning: A preliminary study. Attachment and Human Development, 12, 429-444. doi:

$10.1080 / 14616734.2010 .501967$

Waters, E. (1995). Appendix A: The Attachment Q-SET (Version 3.0). Monographs of the Society for Research in Child Development, 60, 234-246. doi: 10.1111/j.15405834.1995.tb00214.x

Weintraub, S., Dikmen, S. S., Heaton, R. K., Tulsky, D. S., Zelazo, P. D., Bauer, P. J., ... Gershon, R. C. (2013). Cognition assessment using the NIH toolbox. Neurology, 80, S54-64. doi: 10.1212/WNL.0b013e3182872ded.

Williford, A. P., Vick Whittaker, J. E., Vitiello, V. E., \& Downer, J. T. (2013). Children's engagement within the preschool classroom and their development of self-regulation. Early Education and Development, 24, 162-187. doi: 10.1080/10409289.2011.628270

Willoughby, M. T., Blair, C. B., Wirth, R. J., \& Greenberg, M. (2012). The measurement of executive function at age 5: Psychometric properties and relationship to academic achievement. Psychological Assessment, 24, 226-239. doi: 10.1037/a0025361 
Zelazo, P. D. (2006). The Dimensional Change Card Sort (DCCS): A method of assessing executive function in children. Nature Protocols, 1, 297-301. doi: 10.1038/nprot.2006.46

Zelazo, P. D., Anderson, J. E., Richler, J., Wallner-Allen, K., Beaumont, J. L., \& Weintraub, S. (2013). NIH Toolbox Cognition Battery (CB): Measuring executive function and attention. Monographs of the Society for Research in Child Development, 78, 16-33.

doi: 10.1111/mono.12032 
Table 1

Descriptive statistics for the key study measures

\begin{tabular}{lcccc}
\hline & Minimum & Maximum & Mean & $\begin{array}{c}\text { Standard } \\
\text { deviation }\end{array}$ \\
\hline Attachment security & -.46 & .79 & .40 & .25 \\
Backward word span & 0 & 8 & 4.10 & 1.72 \\
DCCS & 0 & 6 & 4.24 & 2.01 \\
NEPSY tower & 4 & 18 & 11.81 & 2.78 \\
Flanker (\% correct answers) & 45 & 100 & 82.30 & 9.69 \\
BRIEF self-control & 26 & 73 & 34.37 & 10.43 \\
BRIEF flexibility & 20 & 52 & 25.12 & 6.91 \\
BRIEF metacognition & 27 & 63 & 32.59 & 7.96 \\
\hline
\end{tabular}


Table 2

Inter-correlations among the EF indicators (zero-order correlations above the diagonal; partial correlations controlling for child age below the diagonal)

\begin{tabular}{|c|c|c|c|c|c|c|c|}
\hline & $\begin{array}{l}\text { Backward } \\
\text { word span }\end{array}$ & DCCS & $\begin{array}{c}\text { NEPSY } \\
\text { tower }\end{array}$ & Flanker & $\begin{array}{c}\text { BRIEF } \\
\text { self-control }\end{array}$ & $\begin{array}{l}\text { BRIEF } \\
\text { flexibility }\end{array}$ & $\begin{array}{c}\text { BRIEF } \\
\text { metacognition }\end{array}$ \\
\hline Backward word span & ------ & $.21 *$ & $.23 *$ & $.34 * * *$ & $-.30 * *$ & $-.31 * * *$ & $-.39 * * *$ \\
\hline DCCS & $.19 *$ & ------ & .14 & $.30 * *$ & $-.26 * *$ & $-.24 *$ & $-.32 * * *$ \\
\hline NEPSY tower & $.22 *$ & .14 & ------ & $.18^{\mathrm{t}}$ & $-.30 * *$ & $-.24 *$ & $-.18^{\mathrm{t}}$ \\
\hline Flanker & $.32 * * *$ & $.30 * *$ & $.17^{\mathrm{t}}$ & ------ & $-.22 *$ & -.12 & $-.36 * * *$ \\
\hline BRIEF self-control & $-.25 * *$ & $-.25 * *$ & $-.29 * *$ & $-.19 *$ & ------ & $.82 * * *$ & $.59 * * *$ \\
\hline BRIEF flexibility & $-.26 * * *$ & $-.22 *$ & $-.23 *$ & -.10 & $.80 * * *$ & ------ & $.52 * * *$ \\
\hline BRIEF metacognition & $-.33 * * *$ & $-.31 * *$ & $-.17^{\mathrm{t}}$ & $-.34 * *$ & $.56 * * *$ & $.48 * * *$ & ------ \\
\hline
\end{tabular}

${ }^{\mathrm{t}} p<.10 ; * p<.05 ; * * p<.01 ; * * * p<.001$ 
Table 3

Zero-order correlations between child EF and child attachment and potential covariates

\begin{tabular}{|c|c|c|c|c|c|c|}
\hline & Child age & Child sex & Birth order & Family SES & $\begin{array}{c}\text { Letter } \\
\text { knowledge }\end{array}$ & $\begin{array}{c}\text { Attachment } \\
\text { security }\end{array}$ \\
\hline Backward word span & $.24 *$ & .06 & -.11 & $.22 *$ & $.44 * * *$ & $.24 *$ \\
\hline DCCS & .10 & .05 & -.02 & $.18^{\mathrm{t}}$ & -.05 & $.19^{*}$ \\
\hline NEPSY tower & .07 & .05 & .18 & .10 & .16 & $.25^{* *}$ \\
\hline Flanker & .12 & .13 & .04 & $.36 * * *$ & .10 & $.31 * * *$ \\
\hline Overall EF task performance & $.25^{*}$ & .10 & -.10 & $.24^{*}$ & $.23^{*}$ & $.37 * * *$ \\
\hline BRIEF self-control & $-.32 * *$ & -.05 & .17 & -.08 & $-.33 * *$ & $-.33 * *$ \\
\hline BRIEF flexibility & $-.31 *$ & .01 & .12 & .01 & $-.22 *$ & $-.37 * * *$ \\
\hline BRIEF metacognition & $-.28^{*}$ & $-.22^{*}$ & .06 & $-.24 *$ & $-.21 *$ & $-.37 * * *$ \\
\hline BRIEF global executive & $-.30 *$ & -.11 & .12 & -.16 & $-.28 * *$ & $-.34 * * *$ \\
\hline
\end{tabular}

Note. Child sex is coded: $1=$ boy; 2 = girl.

${ }^{\mathrm{t}} p<.10 ; * p<.05 ; * * p<.01 ; * * * p<.001$ 
Table 4

Summary of regression analyses predicting teachers' assessment of children's executive function difficulties at school

\begin{tabular}{|c|c|c|c|c|}
\hline Blocks and predictors & BRIEF self-control & BRIEF flexibility & $\begin{array}{c}\text { BRIEF } \\
\text { metacognition }\end{array}$ & $\begin{array}{c}\text { BRIEF global } \\
\text { executive composite }\end{array}$ \\
\hline & $\beta$ & $\beta$ & $\beta$ & $\beta$ \\
\hline 1. Child sex & -.01 & .06 & $-.19 *$ & -.07 \\
\hline Child age & $-.23^{*}$ & $-.26 *$ & $-.28 * *$ & $-.29 * *$ \\
\hline Letter knowledge & $-.28 * *$ & $-.18^{\mathrm{t}}$ & -.12 & $-.22 *$ \\
\hline Family SES & -.01 & .06 & $-.19 *$ & -.07 \\
\hline Weeks of schooling & -.03 & -.11 & -.04 & -.06 \\
\hline 2. Attachment security & $-.16^{\mathrm{t}}$ & $-.21 *$ & $-.21 *$ & $-.24 *$ \\
\hline Attachment unique $\mathrm{R}^{2}(\%)$ & $2.5 \%$ & $4.2 \%$ & $4.3 \%$ & $5.4 \%$ \\
\hline Total $\mathrm{R}^{2}(\%)$ & $17.8 \%$ & $13.7 \%$ & $22.3 \%$ & $21.4 \%$ \\
\hline Model's total F(6,104) & $3.39 * *$ & $2.49 *$ & $4.51 * * *$ & $4.27 * * *$ \\
\hline
\end{tabular}

Note. The coefficients shown are those in the final model, while accounting for all other predictors. Child sex is coded: $1=$ boy; 2 = girl.

${ }^{\mathrm{t}} p<.10 ; * p<.05 ; * * p<.01 ; * * * p<.001$ 
Table 5

Summary of regression analyses predicting children's performance on behavioral EF tasks

\begin{tabular}{|c|c|c|c|c|c|}
\hline Blocks and predictors & $\begin{array}{l}\text { Backward } \\
\text { word span }\end{array}$ & DCCS & NEPSY tower & Flanker & $\begin{array}{c}\text { Overall EF task } \\
\text { performance }\end{array}$ \\
\hline & $\beta$ & $\beta$ & $\beta$ & $\beta$ & $\beta$ \\
\hline 1. Child sex & .14 & -.03 & .06 & .06 & .07 \\
\hline Child age & $.22 *$ & .13 & .11 & .06 & $.23^{*}$ \\
\hline Letter knowledge & $.37 * * *$ & .14 & .07 & -.02 & .12 \\
\hline Family SES & .12 & .15 & .15 & $.34 * * *$ & $.20 *$ \\
\hline Weeks of schooling & -.07 & .07 & .12 & .04 & .01 \\
\hline 2. Attachment security & $.18 *$ & $.24^{*}$ & $.25^{*}$ & $.20 *$ & $.29 * *$ \\
\hline Attachment unique $\mathrm{R}^{2}(\%)$ & $3.1 \%$ & $5.6 \%$ & $5.9 \%$ & $3.8 \%$ & $8.0 \%$ \\
\hline Total $\mathrm{R}^{2}(\%)$ & $32.0 \%$ & $9.6 \%$ & $12.6 \%$ & $17.0 \%$ & $22.2 \%$ \\
\hline Model's total F(6,104) & $7.38 * * *$ & 1.67 & $2.27 *$ & $3.22 * *$ & $4.46 * * *$ \\
\hline
\end{tabular}

Note. The coefficients shown are those in the final model, while accounting for all other predictors.

Child sex is coded: $1=$ boy; 2 = girl.

${ }^{\mathrm{t}} p<.10 ; * p<.05 ; * * p<.01 ; * * * p<.001$ 